\title{
Erratum to: Kevin D. Harrington MD (1938-2013)
}

\author{
John H. Healey MD
}

Published online: 12 July 2013

(C) The Association of Bone and Joint Surgeons (R 2013

\section{Erratum to: Clin Orthop Relat Res DOI 10.1007/s11999-013-3085-5}

In Kevin D. Harrington's obituary, two paragraphs of text were inadvertently published without attribution. The first paragraph in question should read: According to his obituary in the San Francisco Chronicle, a San Francisco native, Dr. Harrington graduated from Lowell High School (1956), Yale University (1960), and the University of California San Francisco (UCSF) School of Medicine with honors (1964). He interned at the Hospital of the University of Pennsylvania in 1965, served 3 years in the US Army (1966-1969), and worked as an orthopaedic resident at UCSF (1969-1972). He was assistant chief of orthopaedic surgery at San Francisco County Hospital from 1972 to 1977 before entering private practice in San Francisco.
The second paragraph should read: According to the obituary, Dr. Harrington volunteered at the Albert Schweitzer Hospital in Haiti and at the "Hole in the Wall Gang" camp, a no-fee program for youth with cancer and other serious illnesses, in Connecticut. Finally, after retiring from private practice in 2003 , he committed his time, talent, and great enthusiasm to the Marin Community Clinics (MCC), where he spearheaded and expanded orthopaedic services to the underserved of Marin County. He was awarded the "Community Champion" award by the MCC in 2012 for his commitment to the ideal "all patients deserve quality care and attention no matter what their financial circumstances."

The author apologizes for these errors.

The online version of the original article can be found under doi:10.1007/s11999-013-3085-5.

J. H. Healey $(\bowtie)$

Orthopaedic Surgery Service, Memorial Sloan-Kettering Cancer

Center, 1275 York Avenue, New York, NY 10021, USA

e-mail: healeyj@mskcc.org 